\title{
Use of $5 \%$ lidocaine medicated plaster to treat localized neuropathic pain secondary to traumatic injury of peripheral nerves
}

\author{
Gerardo Correa-Illanes' \\ Ricardo Roa ${ }^{2}$ \\ José Luis Piñeros ${ }^{2}$ \\ Wilfredo Calderón ${ }^{3}$ \\ 'Rehabilitation Department, ${ }^{2}$ Burns \\ and Plastic Surgery Department, \\ Hospital del Trabajador, ${ }^{3}$ Plastic \\ Surgery Department, Hospital del \\ Salvador, Santiago, Chile
}

This article was published in the following Dove Press journal:

Local and Regional Anesthesia

16 July 2012

Number of times this article has been viewed
Objective: The efficacy of 5\% lidocaine medicated plaster (LMP) has previously been demonstrated in post-traumatic localized neuropathic pain. This study evaluated the use of LMP in localized neuropathic pain secondary to traumatic peripheral nerve injury.

Patients and methods: This prospective observational study enrolled patients with traumatic injuries to peripheral nerves that were accompanied by localized neuropathic pain of more than 3 months duration. Demographic variables, pain intensity (measured using the numeric rating scale; NRS), answers to the Douleur Neuropathique 4 (DN4) questionnaire, and the size of the painful area were recorded.

Results: Nineteen patients were included, aged (mean \pm standard deviation) $41.4 \pm 15.7$ years. Nerve injuries affected the upper (eight patients) or lower (11 patients) limbs. The mean duration of pain before starting treatment with LMP was $22.6 \pm 43.5$ months (median 8 months). Mean baseline values included: NRS $6.7 \pm 1.6$, painful area $17.8 \pm 10.4 \mathrm{~cm}^{2}$ (median $18 \mathrm{~cm}^{2}$ ), and DN4 score $6.7 \pm 1.4$. The mean duration of treatment with LMP was $19.5 \pm 10.0$ weeks (median 17.4 weeks). Mean values after treatment were: NRS $2.8 \pm 1.5$ ( $\geq 3$ point reduction in $79 \%$ of patients, $\geq 50 \%$ reduction in $57.9 \%$ of patients) and painful area $2.1 \pm 2.3 \mathrm{~cm}^{2}$ (median $1 \mathrm{~cm}^{2}, \geq 50 \%$ reduction in $94.7 \%$ of patients). Functional improvement after treatment was observed in 14/19 patients (73.7\%).

Conclusion: LMP effectively treated traumatic injuries of peripheral nerves which presented with chronic localized neuropathic pain, reducing both pain intensity and the size of the painful area.

Keywords: chronic post-surgical pain, chronic post-traumatic pain, $5 \%$ lidocaine medicated plaster, neuropathic pain, peripheral nerve injury

Neuropathic pain (NP) originates as a direct consequence of injury or illness affecting the somatosensory system. ${ }^{1}$ Tending to be more persistent than nociceptive pain and with greater cognitive modulation, it results from a stimulus that would not normally provoke pain and responds only to specific medications. ${ }^{2} \mathrm{NP}$ is generally severe, negatively affects patients' quality of life, and is associated with co-morbidities, such as sleep disturbance, anxiety, depression, and disability. ${ }^{3} \mathrm{NP}$ may occur following nerve injuries, including those from trauma and post-surgical complications. ${ }^{2,4}$ When this occurs after peripheral nerve injury, it is characterized by spontaneous pain in areas of hyposensitivity and/or hypersensitivity, even in patients who show only very slight changes in their neurological examination results. ${ }^{5}$

In 1999, the US Food and Drug Administration approved the use of 5\% lidocaine medicated plaster (LMP) as the first line of medication for treating allodynia generated by post-herpetic neuralgia. ${ }^{6}$ It is a topical peripheral noninvasive analgesic with
Correspondence: Gerardo Correa-Illanes Servicio de Rehabilitación, Hospital del Trabajador de Santiago, Ramón Carnicer 185, Providencia, Santiago, Chile

Tel +5626853I60

$\mathrm{Fax}+5626853180$

Email gcorrea@achs.cl 
minimal systemic absorption, has a low risk of interacting with other medications, possesses an excellent safety and tolerability profile, and has minimal side effects. Since then, LMP has been incorporated in numerous treatment recommendations in the USA, ${ }^{7}$ Europe, ${ }^{8}$ and Latin America, ${ }^{9,10}$ where it is presented as the first line of treatment for localized peripheral neuropathic pain. This may be defined as "a type of neuropathic pain that is characterized by consistent and circumscribed area(s) of maximum pain." 11

The LMP is applied over the area of maximum pain for 12 hours, without the need for titration. This is followed by a 12-hour interval before the next 12-hour application. Clinical studies have shown that a rest period between plaster usage reduces cutaneous exposure and avoids local secondary effects due to occlusion of the affected skin, but nevertheless produces continuous 24-hour analgesia. ${ }^{12,13}$

The small amount of lidocaine that passes from the plaster into the skin is sufficient to reduce pain by stabilizing the membrane and blocking pathological activity from sodium channels in altered nerve fibers. This is achieved without anesthetic effect because the amount absorbed does not block the larger myelin fibers. ${ }^{14}$

The LMP has a "number needed to treat" of 4.4 , with a high grade of efficacy in alleviating peripheral NP. Also, the number of patients who need to be treated for one to suffer an intolerable adverse effect ("number needed to harm") is not significant, being greater than $20 .^{8}$ Around $40 \%$ of patients report pain relief after the second week of use, increasing to $60 \%$ by the fourth week of therapy. ${ }^{15,16}$

The objective of the present study is to complement previous findings and add greater specificity by evaluating the effectiveness and safety of the 5\% LMP in patients with chronic, localized, post-traumatic or post-surgical NP in whom peripheral nerve damage has been clearly diagnosed.

\section{Patients and methods}

An open-ended, observational, clinical study was conducted in a series of patients who attended the Hospital del Trabajador (Worker's Hospital) in Santiago, Chile.

\section{Inclusion and exclusion criteria}

Patients were adults ( $\geq 18$ years) who had localized NP, ${ }^{11}$ which was:

- nonresponsive to oral pharmacological treatment (ie, patients experienced insufficient pharmacological effect or were intolerant to the secondary effects of analgesia)

- of more than 3 months duration
- secondary to a confirmed unilateral injury of sensory or mixed peripheral nerve on an extremity, caused by either trauma or surgery.

Patients were excluded if they had open skin lesions, severe neurological disturbances, or severe psychiatric disorders.

\section{Evaluations}

A structured protocol was applied that took into account demographic variables, diagnoses, causes of pain, and mental health. A DN4 questionnaire ${ }^{17,18}$ was administered by the attending clinician for all patients; this considers pain to be neuropathic when the score is $\geq 4 / 10$ points. Peripheral nerve injury was clinically verified in all patients by a detailed history and physical examination, which included sensory and motor deficits relating to the skin and musculature innervated by the affected nerve. All patients presented with localized and detectable superficial pain. The painful areas were evaluated for the presence of mechanical static allodynia (pain provoked by light pressure with the index finger), dynamic allodynia (pain provoked by light brushing), and hyperalgesia (evaluated as an exaggerated painful response to a prick compared to a control site). The width and length of the painful area was measured by the patient's response to pain at the time of the examination and was photographed.

In all cases, complementary studies were conducted to define the peripheral nerve damage. A neurophysiological profile was established with Cadwell equipment (Cadwell Sierra Wedge; Cadwell Laboratories, Kennewick, MA) according to clinical guidelines established by the American Academy of Electrodiagnostic and Neuromuscular Medicine. A bilateral neurographic sensory evaluation was carried out, which was considered pathological if sensory action potentials on the affected side were decreased by $\geq 50 \%$ compared to the healthy side. ${ }^{6}$ Soft tissue was evaluated with ultrasound using Phillips equipment (Phillips IU 22, 7-17 MHz and 5-12 MHz transducers; Phillips, Seattle, WA) to detect peripheral nerve injury due to trauma, neuromas, and compression. ${ }^{19,20}$

\section{Intervention}

The 5\% LMP (Versatis; Grünenthal GmbH, Aachen, Germany) was applied over the area of maximum pain. The initial dose (the size of the plaster), use of co-analgesics, and concomitant medications were recorded. Patients who were receiving analgesics maintained their current dose but were able to reduce or discontinue this medication during 
LMP treatment. No new or additional analgesic medication was introduced during the LMP treatment phase.

In all cases, patients applied the LMP to intact, dry, nonirritated skin for periods no longer than 12 consecutive hours over the previously determined site of maximum pain. Hypoallergenic adhesive (Micropore Surgical Tape; 3M laboratories, St Paul, MN, USA) was used to ensure adhesion to the skin. The LMP was applied at night for better adhesion because of the location of the injuries (extremities) and because the patients were physically active during the day.

Therapy results were expressed as absolute and percentage changes in the numeric rating scale (NRS), area of pain, presence of allodynia, sleep quality, recovery of function, and return to work. Patients were seen monthly, and the described protocol was applied at each visit.

LMP therapy was considered effective if it produced one or more of the following: a decrease in the NRS of $\geq 3$ points; a reduction in the NRS of $\geq 50 \%$; or a decrease in the painful area of $\geq 50 \%$, from the corresponding value observed at baseline. An improvement in function was considered significant if a patient reported an enhancement of his/her physical condition that was important socially or for employment purposes.

We considered the maximum effect of the LMP to have been achieved when no further changes were observed in the three parameters mentioned above. Patients were followed up for 18 months.

\section{Ethical aspects}

The Ethical Committee of the Hospital del Trabajador of Santiago approved the study. Although LMP has only been approved by the Chilean health authorities for post-herpetic neuralgia, the Pharmacy Committee of the Hospital del Trabajador of Santiago approved its in-house use for neuropathic post-traumatic pain in 2008 . The study was conducted in accordance with the principles of the Declaration of Helsinki and Good Clinical Practice.

All patients were appropriately informed about the characteristics of the medication and its side effects before enrolling, and all gave their written informed consent before participating. During each interview the side effects were discussed as well as the importance of adhering to the treatment regimen. All patients who received an electrophysiological examination signed an informed consent form relating to the possible risks involved.

\section{Statistical analysis}

For the analysis of quantitative variables, we used an average standard deviation and maximum-minimum values.
Qualitative variables were summarized by means of absolute frequencies and relative percentages. To compare mean values in the same patients studied during two phases of the investigation, the paired Student $t$-test was used. The correlation coefficient $(r)$ was used to evaluate the correlation between two variables.

\section{Results}

Between October 2008 and August 2011, 19 patients with post-traumatic, chronic, localized, neuropathic pain secondary to a peripheral nerve injury were enrolled in the study.

\section{Demographics}

The study population consisted of 15 men and four women, with an average age of $41.4 \pm 15.7$ years (range $20-84$ years). The traumatic injuries were located on the lower limb in 11 patients $(57.9 \%)$ and on the upper limb in eight patients $(42.1 \%)$. The causes of injury were burns in seven cases (36.8\%), soft tissue trauma (crush and/or de-gloving) in five patients $(26.3 \%)$, post-surgical injuries in four patients $(21.1 \%)$, and fractures in three patients $(15.8 \%)$.

\section{Evaluation of the peripheral nerves}

Nerve injury corresponded to sensory nerves in 14 cases (superficial radial, palmar branch and median collateral palmars, femoral cutaneous, internal saphenous, and sural) and mixed nerves in five patients (common peroneal and posterior tibial). A neurophysiological test was carried out on 18 patients $(95 \%)$, with significant neurophysiological effects observed in all cases. The patient for whom no examination was carried out was a wrist-level amputee with a recurrent neuroma of the radial superficial nerve, who had undergone surgery on three occasions and was evaluated with ultrasound. Seventeen patients were examined with ultrasound; altered morphology was observed in seven patients $(36.8 \%)$, four of whom presented with neuroma and three with fusiform thickening of the affected peripheral nerve. In two patients $(10.5 \%)$ nerve damage was confirmed during surgery.

\section{Initial pain evaluation}

The peripheral nerves most compromised were the superficial radial nerve and the internal saphenous nerve (Table 1). The mean intensity of pain (NRS) at the beginning of the study was $6.7 \pm 1.6$ (median 7), ranging between 4 and 10 points. Eleven patients $(57.9 \%)$ presented with an NRS score of $\geq 7$ points. The mean duration of pain before initiating LMP treatment was $22.6 \pm 43.5$ months, with a median of 8 months (range 3 months to 16 years) (Table 2). 
Table I Peripheral nerve damage in patients $(n=19)$ with post-traumatic neuropathic pain who were treated with the $5 \%$ lidocaine medicated plaster

\begin{tabular}{ll}
\hline Injured nerve & Number of patients \\
\hline Superficial radial & 4 \\
Internal saphenous & 4 \\
Common peroneal & 3 \\
Collateral palmar & 3 \\
Posterior tibial & 2 \\
Median (palmar branch) & $\mathrm{I}$ \\
Femoral cutaneous & $\mathrm{I}$ \\
Sural & $\mathrm{I}$ \\
\hline
\end{tabular}

\section{Pain area and doses used}

At the beginning of the study, the mean painful area was $17.8 \mathrm{~cm}^{2}$ with a median of $18 \mathrm{~cm}^{2}$ (range $1-44 \mathrm{~cm}^{2}$ ). All patients had the lidocaine plaster applied to the painful area, with one patient receiving one half of a plaster and the other 18 receiving one quarter of a plaster.

\section{Presence of neuropathic pain}

Following application of the DN4 questionnaire, the mean score of the population studied was $6.7 \pm 1.4$ points, median 6 points. Eight patients $(42.1 \%)$ presented with tactile dynamic allodynia. In 14 cases (73.7\%) the Tinnel sign was observed, with radiation of pain over the area of the affected nerve.

\section{Co-morbidity}

Fourteen patients $(73.7 \%)$ required treatment for mental illness resulting from the traumatic pathology that produced NP. The most frequent diagnoses were adaptive disturbance, anxiety, depression or a combination of these (12 cases), post-traumatic stress disorder (two cases), and major depression (one case).

\section{Concomitant analgesia}

At the beginning of the study, 10 patients (52.6\%) used LMP as monotherapy and nine patients (47.4\%) received one or more concomitant analgesic drugs. These included sustained release tramadol (eight cases), paracetamol (acetaminophen; four cases), transdermal buprenorphine (one case), tramadol drops (five cases), pregabalin (five cases), and gabapentin (one case).

Table 2 Time from onset of pain to initial use of the $5 \%$ lidocaine medicated plaster

\begin{tabular}{ll}
\hline Time from onset of pain to initial use & Number of patients (\%) \\
\hline 3 to 12 months & $12(63.2 \%)$ \\
$>12$ months & $7(36.8 \%)$ \\
\hline
\end{tabular}

\section{Pain evaluation after treatment}

After 12 weeks of treatment with LMP, 37\% of patients had achieved stable analgesia. After an average of $19.5 \pm 10$ weeks of treatment, (median 17.4 weeks, range 4-21 weeks) all patients had achieved stable analgesia. The mean reduction in NRS score was 3.9 points, (median 3 points, range 2-8 points), equivalent to a reduction of $58.2 \%$ in terms of the baseline pain score (Figure 1).

Fifteen patients $(78.9 \%)$ reduced their NRS score by 3 points or more, 11 patients $(57.9 \%)$ lowered their NRS by $50 \%$ or more, and no patient maintained an NRS score of $\geq 7$ (Table 3 ). In eight patients who had brushing allodynia at the beginning of the study, this ceased with the LMP treatment. The area of pain was reduced by an average of $38.8 \%$ at 4 weeks and by an average of $67.1 \%$ at 12 weeks. The maximum reduction was at 19.5 weeks, with a mean decrease of $15.6 \pm 9.3 \mathrm{~cm}^{2}$ (paired Student $t$-test, $P<0.0005$, median $13 \mathrm{~cm}^{2}$ ), equivalent to a reduction of $87.6 \%$. Eighteen patients $(94.7 \%)$ reduced their area of pain by $50 \%$ or more (Table 3 ), and 14 patients (73.7\%) declared they had significant functional recuperation after use of the LMP (Table 4). No correlation was observed between the initial DN4 score and the decrease in NRS score following treatment with LMP $(r=0.431)$.

\section{Labor impact}

Before the painful injury, 18 of the 19 patients were actively working. At the beginning of the treatment with LMP, only 13 patients were working. After the treatment with LMP, three of the five patients who were not working returned to work.

\section{Evolution of analgesic co-medication}

After 19 weeks of treatment, one-third of the original analgesic co-medications had been discontinued. At the end of the study, 11 patients (57.9\%) were using LMP as monotherapy and eight patients $(42.1 \%)$ continued to receive concomitant analgesia.

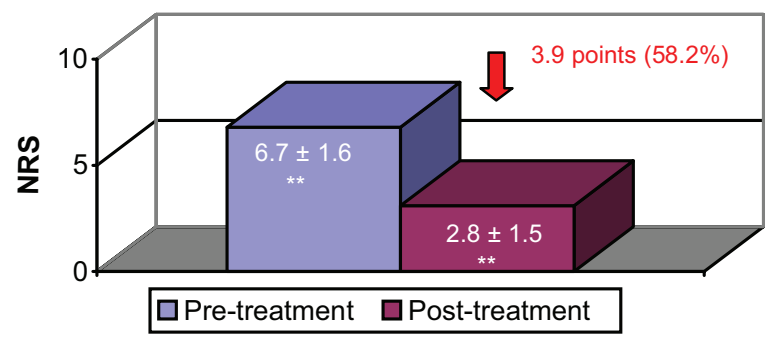

Figure I Mean intensity of pain (NRS) before and after treatment with $5 \%$ lidocaine medicated plaster.

Note: **Paired Student $t$-test, $P<0.0005$.

Abbreviation: NRS, Numeric rating scale. 
Table 3 Percentage reduction in pain score and painful area for patients treated with the $5 \%$ lidocaine medicated plaster

\begin{tabular}{llll}
\hline $\begin{array}{l}\text { Percentage } \\
\text { reduction in } \\
\text { initial NRS (\%) }\end{array}$ & $\begin{array}{l}\text { Number of } \\
\text { patients (\%) }\end{array}$ & $\begin{array}{l}\text { Percentage } \\
\text { reduction in } \\
\text { painful area (\%) }\end{array}$ & $\begin{array}{l}\text { Number } \\
\text { of patients (\%) }\end{array}$ \\
\hline $75 \%$ to $100 \%$ & $4(21.1 \%)$ & $75 \%$ to $100 \%$ & $16(84.2 \%)$ \\
$50 \%$ to $74 \%$ & $7(36.8 \%)$ & $50 \%$ to $74 \%$ & $2(10.5 \%)$ \\
$25 \%$ to $49 \%$ & $8(42.1 \%)$ & $25 \%$ to $49 \%$ & $1(5.3 \%)$ \\
$0 \%$ to $24 \%$ & 0 & $0 \%$ to $24 \%$ & $0(0 \%)$ \\
Total & $19(100 \%)$ & Total & $19(100 \%)$ \\
\hline
\end{tabular}

Abbreviation: NRS, numeric rating scale.

Of the eight patients who continued to take supportive analgesics, five maintained their use of tramadol sustainedrelease formulation, two used tramadol drops for incidental pain, one used acetaminophen $(1500 \mathrm{mg})$, two used pregabalin (75 and $150 \mathrm{mg}$ ), and one used gabapentin (400 mg).

Eighteen months after starting treatment, only eight (42.1\%) of the original 19 patients were still using the LMP. Two of these eight patients were using LMP as monotherapy. In the other 11 cases, LMP had been discontinued as a result of the reduction or absence of pain.

\section{Tolerability}

None of the patients reported adverse local or systemic reactions to the use of LMP.

\section{Treatment adherence}

Patient adherence to treatment was excellent in all cases. We observed a high level of satisfaction in patients owing to the ease of use and absence of side effects.

\section{Discussion}

The presence of chronic post-traumatic or post-surgical pain is a common event. The frequency, prevalence, and clinical course of these painful neuropathies are not exactly known. $^{21}$

In recent years, various epidemiological and clinical studies have aimed to characterize the neuropathic pain produced

Table 4 Improved function in patients treated with the $5 \%$ lidocaine medicated plaster

\begin{tabular}{ll}
\hline Functional property evaluated & $\begin{array}{l}\text { Number of patients } \\
\text { with improvement (\%) }\end{array}$ \\
\hline Daily activities & $5(26.3 \%)$ \\
Ability to walk & $4(21.1 \%)$ \\
Increased tolerance of the bipedal position & $2(10.5 \%)$ \\
Sleep quality & $2(10.5 \%)$ \\
Increased tolerance in use & I (5.3\%) \\
of upper extremity prosthesis & \\
\hline
\end{tabular}

by peripheral nerve injuries. These studies identified two main subgroups of patients with NP resulting from peripheral nerve injury: one with a minor sensory deficit plus hyperalgesia/ mechanical allodynia and the other with hypoesthesia and a pronounced deficit in thermal and pain sensitivity. ${ }^{6}$

Ciaramitaro et al published an epidemiological study of NP and traumatic peripheral nerve injuries in $2010 .^{2}$ In 1 year they analyzed 211 injuries, principally in young men and predominantly affecting the upper extremities. Of these patients, $50 \%$ presented with NP, which was classified as moderate to severe in $79 \%$ of cases. In this study, the radial and ulnar nerves were the most frequent sites of pain from nerve injury in the upper extremities, and the peroneal and sciatic nerves in the lower extremities. The presence of NP was associated with a decreased quality of life in patients with traumatic neuropathies. ${ }^{2}$

Taylor et a ${ }^{22}$ compared two patient populations with post-operative peripheral nerve injuries (median and cubital) and found that those with NP exhibited severe sensory motor impairment and deteriorating nervous regeneration. They also scored more highly on neuroticism and pain-catastrophizing scales. $^{22}$

The presence of spontaneous pain after nerve damage may be related to alterations in nociceptor channel activity. Allodynia, caused by mechanical pressure, and abnormal temporal summation of acute pain have been observed in post-mastectomy and post-inguinal herniotomy patients, suggesting that peripheral and/or central hyperexcitability contribute to the presence of spontaneous pain. ${ }^{23}$ The latter may be confirmed by the suppressor effect of lidocaine on the spontaneous and evoked abnormal activity that initiates and maintains NP. As a local anesthetic, lidocaine acts as a nonselective block on voltage-dependent sodium channels (Nav 1.7, Nav 1.8, and Nav 1.9, both open and inactive), which are located in the excitable membranes of afferent primary $\mathrm{C}$ and $\mathrm{A}-\delta$ fibers and are responsible for nerve conduction from damaged peripheral nociceptors. . $^{14,21,24}$

Attal et $\mathrm{al}^{25}$ observed that administering intravenous lidocaine in 22 patients with pain due to peripheral nerve damage - including 14 post-trauma patients - decreased spontaneous pain, tactile dynamic allodynia, and static (punctate) mechanical allodynia/hyperalgesia. The effects of lidocaine on spontaneous pain intensity were significantly higher in patients with mechanical allodynia than in those without allodynia. It was concluded that patients with mechanical allodynia may be good candidates for treatment with local anesthetic-like drugs and possibly with other sodium-channel blockers. ${ }^{25}$ 
To date, various studies have been published on the use of LMP for post-traumatic NP. ${ }^{3,21,26-29}$ One of the first studies ${ }^{21}$ evaluated the use of LMP in 40 patients with chronic, severe, post-traumatic, cutaneous pain of surgical and nonsurgical origin. The investigators observed a significant decrease in pain intensity at 4 and 12 weeks.

Correa-Illanes et $\mathrm{al}^{27}$ observed a significant decrease in the intensity of pain and the painful area following treatment with LMP in patients with localized, post-traumatic/postsurgical, moderate to severe NP.

Nicolaou et $\mathrm{al}^{28}$ observed good or very good improvement in $75 \%$ of patients treated with LMP. Among their series of 106 patients, 15 presented with post-traumatic and postsurgical NP of the extremities, especially the knees. Nicolaou et al observed that patients with allodynia, hyperalgesia, and spontaneous burning pain were good candidates for LMP.

Delorme et $\mathrm{al}^{3}$ conducted a retrospective study that evaluated the use of LMP in patients presenting mainly with post-traumatic NP $(n=99)$ and post-surgical NP $(n=325)$. Fifty-six percent of the patients presented with allodynia. Following treatment with LMP, $45.5 \%$ of the patient sample had reduced the intensity of NP by more than $50 \%$.

In our experience, LMP is an efficient medication for managing localized NP following injury to peripheral nerves as a result of trauma or surgery. In two-thirds of our patients, the functional condition at discharge had improved with LMP treatment. However, limitations of this study include the small number of patients and the absence of a control group.

Our series contributes to previously published articles, ${ }^{3,21,27-29}$ because of the inclusion of a younger population in active employment with well-defined unilateral peripheral nerve injury to the extremities, in which the DN4 questionnaire was applied. Also, the limits of the painful area were marked and measured, and this parameter was included in evaluating the response to treatment with LMP. Reducing the painful area has important functional benefits, especially when pain is located on the palms of the hands or the soles of the feet.

The average dose used in our series was one quarter of a plaster per day - less than other studies ${ }^{3,27}$ - demonstrating economic advantages compared to the average cost of other proposed medical products. Results from our study suggest that the LMP provides benefits by reducing prescriptions for other analgesics and reducing morbidity, particularly in actively working populations who may operate heavy machinery, high-risk elderly populations, and patients who have deteriorating vital functions (hepatic, renal, or cardiovascular insufficiency).
The therapeutic use of topical analgesia for treating posttraumatic NP where there is a high incidence of mental health pathology that requires multi-medication, as in our series, has the additional advantage of avoiding pharmacological interactions and accumulation of side effects.

As with previous studies, ${ }^{3,27-29}$ our results demonstrate the efficacy of the LMP and its excellent safety profile with very few adverse local reactions, along with the simplification of treatment schemes and a reduction in concomitant medication.

\section{Conclusion}

The LMP is an effective, safe, and comfortable option in the treatment of patients with localized neuropathic pain secondary to a peripheral nerve injury. The LMP also significantly improves the functional level of patients and their re-integration into the work force.

\section{Acknowledgments}

I thank my department chief and colleagues at the Rehabilitation Service of the Hospital del Trabajador of Santiago, Chile, for their support during this study, and Derrick Garwood Ltd, Cambridge, UK, for editorial support. The production of this manuscript was sponsored by Grünenthal $\mathrm{GmbH}$, Aachen, Germany.

\section{Disclosure}

GC has had a previous consultancy relationship with Grünenthal GmbH. RR, JLP, and WC have no financial or other relationships to declare.

\section{References}

1. Treede R, Jensen T, Campbell JN, et al. Neuropathic pain. Redefinition and a grading system for clinical and research purposes. Neurology. 2008;70:1630-1635.

2. Ciaramitaro P, Mondelli M, Logullo F, et al. Traumatic peripheral nerve injuries: epidemiological findings, neuropathic pain and quality of life in 158 patients. J Periph Nerv Sys. 2010;15:120-127.

3. Delorme C, Navez ML, Legout V, Deleens R, Moyse D. Treatment of neuropathic pain with 5\% lidocaine-medicated plaster: Five years of clinical experience. Pain Res Manag. 2011;16:259-263.

4. Hernández N, Hernández J, Moreno C. Use of lidocaine patches in the relief of localised neuropathic pain. Rev Iberoamericana del Dolor. 2009;1(4):13-28.

5. Finnerup NB, Sindrup SH, Jensen TS. Chronic neuropathic pain: mechanisms, drug targets and measurement. Fundam Clin Pharmacol. 2007;21:129-136.

6. Schüning J, Scherens A, Haussleiter IS, et al. Sensory changes and loss of intraepidermal nerve fibers in painful unilateral nerve injury. Clin $J$ Pain. 2009;25:683-690.

7. Dworkin R, O'Connor A, Audette J, et al. Recommendations for the pharmacological management of neuropathic pain: an overview and literature update. Mayo Clin Proc. 2010;85(Suppl 3):S3-S14.

8. Finnerup N, Sindrup S, Jensen T. Recent advances in pharmacological treatment of neuropathic pain. F1000 Med Rep. 2010;2:52. 
9. Acevedo JC, Amaya A, de León-Casasola O, et al. Guías para el diagnóstico y el manejo del dolor neuropático:consenso de un grupo de expertos latinoamericanos. Rev Iberoamericana del Dolor. 2008;2: 15-46.

10. Asociación Chilena para Estudio del Dolor (AChED). Guías para la Definición y el Manejo del Dolor Neuropático Localizado. Consenso Chileno. El Dolor. Octubre 2011. Edición especial.

11. Mick G, Baron R, Finnerup NB, et al. What is localized neuropathic pain? A first proposal to characterize and define a widely used term. Pain Management. 2012;2(1):71-77.

12. Haanpää M. Mechanism-based treatment of herpes zoster and postherpetic neuralgia. Europ J Pain. 2007;11(S1):S38.

13. Rehm S, Binder A, Baron R. Post-herpetic neuralgia: 5\% lidocaine medicated plaster, pregabalin, or a combination of both? A randomized, open, clinical effectiveness study. Curr Med Res Opin. 2010;26(7): $1607-1619$.

14. Wasner G, Kleinert A, Binder A, Schattschneider J, Baron R. Postherpetic neuralgia: topical lidocaine is effective in nociceptordeprived skin. J Neurology. 2005;252(6):677-686.

15. Katz NP, Gammaitoni A, Davis M, et al. Lidocaine patch 5\% reduces pain intensity and interference with quality of life in patients with postherpetic neuralgia: an effectiveness trial: the Lidoderm Patch Study Group. Pain Med. 2002;3(4):324-332.

16. Galer B, Jensen MP, Ma T, Davies PS, Rowbotham MC. The lidocaine patch 5\% effectively treats all neuropathic pain qualities: results of a randomized, double-blind, vehicle-controlled, 3-week efficacy study with use of the neuropathic pain scale. Clin J Pain. 2002;18(5):297-301.

17. Bouhassira D, Attal N, Alchaar H, et al. Comparison of pain syndromes associated with nervous or somatic lesions and development of a new neuropathic pain diagnostic questionnaire (DN4). Pain. 2005;114(1-2):29-36.

18. Perez C, Galvez R, Huelbes S, et al. Validity and reliability of the Spanish version of the DN4 (Douleur Neuropathique 4 questions) questionnaire for differential diagnosis of pain syndromes associated to a neuropathic or somatic component. Health Qual Life Outcomes. 2007;5:66.
19. Shafighi M, Gurunluoglu R, Ninkovic M, Mallouhi A, Bodner G. Ultrasonography for depiction of brachial plexus injury. J Ultrasound Med. 2003;22(6):631-634.

20. Provost N, Bonaldi VM, Saravin L. Amputation stump neuroma: Ultrasound features. J Clin Ultrasound. 1997;25(2):85-89.

21. Hans G, Joukes E, Verhulst J, Vercauteren M. Management of neuropathic pain after surgical and non-surgical trauma with lidocaine $5 \%$ patches: study of 40 consecutive cases. Curr Med Res Opin. 2009; 25(11):2737-2743.

22. Taylor KS, Anastakis DJ, Davis KD. Chronic pain and sensorimotor deficits following peripheral nerve injury. Pain. 2010;151:582-591.

23. Landerholm AH, Ekblom AG, Hansson PT. Somatosensory function in patients with and without pain after traumatic peripheral nerve injury. Eur J Pain. 2010;14:847-853.

24. de Leon-Casasola OA. Multimodal approaches to the management of neuropathic pain: The role of topical analgesia. J Pain Symp Manag. 2007;33:356-364

25. Attal N, Cruccu G, Baron R, et al. EFNS guidelines on the pharmacological treatment of neuropathic pain: 2010 revision. Eur J Neurol. 2010;17:1113-e88.

26. Nayak S, Cunliffe M. Case report: Lidocaine 5\% patch for localized chronic neuropathic pain in adolescents: report of five cases. Pediatr Anaesth. 2008;18(6):554-558.

27. Correa-IIlanes G, Calderon WO, Roa RG, Piñeros JB, Dote JA, Medina DG. Treatment of localized post-traumatic neuropathic pain in scars with 5\% lidocaine medicated plaster. Local and Regional Anesthesia. 2010;3:77-83.

28. Nicolaou A, Nicholson B, Hans G, Brasseur L. Outcome predictors for treatment success with 5\% lidocaine medicated plaster in low back pain with neuropathic components and neuropathic pain after surgical and nonsurgical trauma. J Pain Research. 2011;4:25-38.

29. Wilhelm IR, Tzabazis A, Likar R, Sittl R, Griessinger N. Long-term treatment of neuropathic pain with a $5 \%$ lidocaine medicated plaster. Eur J Anaesthesiol. 2010;27(2):169-173.
Local and Regional Anesthesia

\section{Publish your work in this journal}

Local and Regional Anesthesia is an international, peer-reviewed, open access journal publishing on the development, pharmacology, delivery and targeting and clinical use of local and regional anesthetics and analgesics. The journal welcomes submitted papers covering original research, basic science, clinical studies, reviews \& evaluations,

\section{Dovepress}

guidelines, expert opinion and commentary, case reports and extended reports. The manuscript management system is completely online and includes a very quick and fair peer-review system, which is all easy to use. Visit http://www.dovepress.com/testimonials.php to read real quotes from published authors. 